Jeffrey D. Sachs

The Ages of

Globalization

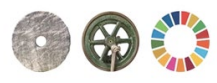

Geography, Technology, and Institutions

\title{
The Ages of Globalization: Geography, Technology, and Institutions
}

By Jeffrey D. Sachs

COLUMBIA UNIVERSITY PRESS: 2020. 280PP. \$24.95

A history of globalization can offer important lessons to help navigate the challenges of the twenty-first century, and manage modern globalization successfully. This is Jeffrey Sachs' motivation in The Ages of Globalization, a concise and informative overview of the main drivers of global transformation.

Sachs guides the reader through seven globalization periods: Palaeolithic, Neolithic, Equestrian, Classical, Ocean, Industrial and Digital - the remaining one is ongoing. He explores how the interplay between geography, technology and institutions shaped each age, and what factors paved the way from one epoch to another. He identifies three major challenges of the digital age - inequality, environmental degradation and geopolitical risks - and proposes five pillars to overcome them: sustainable development, epitomized by the United Nations Sustainable Development Goals; social-democratic ethos; subsidiarity; a reformed United Nations; and a world safe for diversity. Although food is not the main theme of the book, the evolution of agriculture and its crucial roles as an enabler and an outcome of globalization are clear throughout the narrative. Productivity gains have allowed labour to be freed up for other activities, and food production has been increasingly shaped by international trade, economic scale and digital technologies.

Sachs, as always, does a good job in bringing together big abstract ideas for a global analysis, and this book might appeal to those interested in a holistic view of development. By drawing on lessons from the seven ages, he highlights the need for concerted action - to avoid conflict, keep the planet habitable and promote a just and inclusive society.

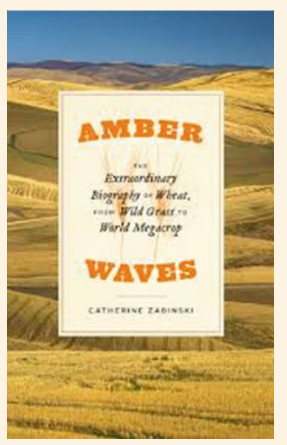

\section{Amber Waves: The Extraordinary Biography of Wheat, from Wild Grass to World Megacrop} By Catherine Zabinski UNIVERSITY OF CHICAGO PRESS: 2020. 216PP. \$24.00

Wheat was among the first grains to be cultivated and it is now one of the most important staple crops in the world. In Amber Waves, Catherine Zabinski - an ecologist at Montana State University - tells the story of wheat from its origin, domestication and genetic improvement, and the history of its production, processing and trade. Moreover, Zabinski proposes that the biography of wheat is not simply the story of a crop - it is a thread in the history of humans seeking food security.

Wheat grew on the planet for millions of years before our ancestors discovered its value as food. From the early days of agriculture, the grasses witnessed human cultural evolution; centuries of change in farming methods, and agricultural technologies that developed along the way with human civilization. Zabinski discusses the contribution of the Green Revolution and biotechnology to increasing wheat production in modern agriculture, and explores the future of wheat and sustainable production.

This story about the complex relationship between humans and crops should appeal to plant scientists in particular,and indeed the general public. 


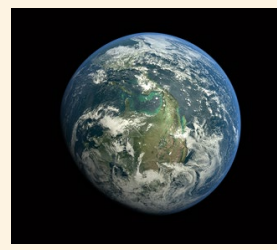

The Food Chain: Made in Space

Presented by Graihagh Jackson

Podcast from The Food Chain, BBC World Service (https://www.bbc.co.uk/programmes/w3csyp1n)

Space presents many challenges for growing fresh food - the most difficult being a lack of air.

In this 27 min episode of The Food Chain, we discover how collaborative work with NASA and the International Space Station (ISS) promises more resilient agriculture in space and on Earth.

The leader of NASA's Vegetable Production System (Veggie) project, Dr Gioia Massa, describes how two tiny $13 \mathrm{~cm}^{2}$ greenhouses on the ISS are providing exciting findings on microgravity and the plasticity of plants under gravitational stress. The results, we are told, are safe to eat and ISS astronauts can enjoy fresh space-grown red romaine lettuce and Tokyo Bekana cabbage.

Microgravity is also of interest to entrepreneurs. In March, a group of investors sent Merlot and Cabernet vines to the ISS with the aim of 'speeding up' the vines' stress adaptation responses.

When the plants return to Earth later this year, it is hoped that a climate-resilient vine may have been created - without the need for genetic modification.

Back on Earth, we learn how technology developed for space has inspired breakthroughs in indoor vertical farming, and that proprietary polymers designed by NASA for space suits accelerated the development of time-released fertilizer coatings.

The ISS may be out of this world, but it still has a problem that researchers on Earth are very familiar with - a lack of freezer space - which is limiting the speed at which food experiments can be performed.

This podcast is suitable for both scientists and non-scientists, and a nice entry-point for discovery of how space science could, someday, end up on your dinner table. Image credit: Vitalij Cerepok/Eyeem/Eyeem/Getty

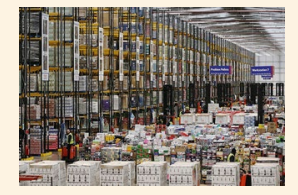

\section{COVID-19: The Food Dimension}

\section{Presented by Dan Saladino}

Podcast from The Food Programme, BBC Radio 4 (https://www.bbc.co.uk/sounds/play/m000gcwf) COVID-19 is testing not just public health and public finances, but also our food systems. The challenges are addressed with clarity and gravity in this 28 min podcast.

An unnerving account of power play and leadership in the UK food system, exposed by the current crisis, is a major theme of the podcast. Carina Perkins, managing editor of The Grocer magazine and Tim Lang of City University, London, relate what appears to have been an initially complicated dynamic between government and the retail sector in coordinating insights, intelligence and - most importantly - action regarding national food supply.

We are reassured that there is plenty of food in the supply chain, but unprecedented demand. The podcast questions whether central intervention is required; it is asserted that much of the responsibility for discouraging panic buying and stockpiling, and ensuring that food is available to the vulnerable in society, has been taken by - or has been left to - the retail sector. Is it the role of retailers to actively manage food provision? Are there adequate social safety nets for the vulnerable in society, including the 2 million people in the UK who rely on food banks? Another theme of the podcast is zoonosis. Andrew Cunningham from the Zoological Society of London provides fascinating examples of how altered land use in intensified agriculture can facilitate the transfer of disease between animals and humans. Evidence points to live animal markets in Wuhan as the origin of the COVID-19 pandemic. According to the podcast, these markets are a relatively recent phenomenon of new affluence in China; and as humans are increasingly exposed to the diversity of wild animals purchased and slaughtered at markets, they are also exposed to new pathogens.

This podcast is a comprehensive account of shock pressures on food systems. It is detailed and informative, political, scientific and wholly relatable. It would appeal to a scientific and public audience interested in the food supply chain under pressure, and food policy in crises. Image credit: Dan Kitwood/Staff/Getty Images News/Getty

Published online: 17 April 2020

https://doi.org/10.1038/s43016-020-0064-3 